\title{
Predicting pubertal development by infantile and childhood height, BMI, and adiposity rebound
}

\author{
Alina German', Michael Shmoish² and Ze'ev Hochberg ${ }^{3}$
}

BACKGROUND: Despite substantial heritability in pubertal development, children differ in maturational tempo. Hypotheses: (i) puberty and its duration are influenced by early changes in height and adiposity. (ii) Adiposity rebound (AR) is a marker for pubertal tempo.

METHODS: We utilized published prospective data from 659 girls and 706 boys of the Study of Early Child Care and Youth Development. We investigated the age of pubarche-thelarchegonadarche -menarche as a function of early height, BMI, and AR.

RESULTS: In girls, height standard deviation scores correlated negatively with thelarche and pubarche from 15 mo of age and with menarche from $54 \mathrm{mo}$. BMl correlated negatively with thelarche from 36 mo of age and menarche from 54 mo. In boys, age at gonadarche correlated negatively with height from 36 mo of age. An AR was detected in 47\% of girls and $55 \%$ of boys, who became heavier and had earlier and faster puberty than those with no AR.

CONCLUSION: The onset and tempo of puberty are influenced by a two-hit program. The first is exerted during the infancy-childhood transition (ICT; 6-12 mo) and includes height, as an early predictor of maturational tempo. The second hit occurs at the childhood-juvenility transition (5-7 y) and is based on adiposity and its rebound.

$\mathbf{T}$ he physiological variation in the age at the onset of puberty can be $4-5$ y in normal children whose life conditions are comparable and greater in children whose life conditions vary (1). Despite substantial heritability in pubertal development (2), children differ in their maturational tempos (3), and this difference generates plasticity in their phenotypic trajectories so that they can adapt to their specific environment $(4,5)$. The influence of socioeconomic status, diet, exercise, prepubertal fat and body weight, chronic illness, and stress on the age of the onset of puberty is well documented (1). The influence of nutritional cues on the age at the onset of puberty are distinctly temporal: they tend to cause (i) early maturity in children whose average body mass in early life is either lower or higher than average and (ii) late maturity in children whose weight gain during childhood is low (1). As a result, the pattern of growth in these late maturing children is U-shaped (6,7). During the transition from childhood to juvenility, which usually occurs when children are aged about $6 \mathrm{y}$, the BMI rebounds immediately after it reaches its nadir-the so-called adiposity rebound (AR) $(8,9)$. A young age and a high BMI at the age of rebound predicts a high BMI in early adulthood, and it has been suggested that the occurrence of a high BMI at $3 \mathrm{y}$ of age leads to a rebound at a younger age (10).

Since height and BMI at certain critical ages can predict the timing and duration of puberty, the working hypotheses of this investigation are (i) the onset of puberty, menarche, and pubertal progression and duration are influenced by early changes in height and adiposity and (ii) the age of occurrence of AR is an important marker of maturational tempo. Hence, the purpose of this investigation was to examine the height and BMI at different ages as they may predict pubertal timing and duration. To this end, we examined pubertal variability by assessing the effects of height, BMI, and AR at specific ages on the timing and duration of puberty. For this purpose, we utilized the anthropological measurements and pubertal staging data from American children of families that were recruited at $1 \mathrm{y}$ of age in 1991 and followed up prospectively until 15.5 $y$ of age for the National Institutes of Health (NICHD) Study of Early Child Care and Youth Development (SECCYD) (11).

\section{RESULTS}

Pubertal development in boys and girls were assessed by clinical investigators of the SECCYD study and compared with the progress in the subjects' BMI. In girls, thelarche occurred at $9.8 \pm 0.7 \mathrm{y}$, pubarche occurred at $10.3 \pm 0.7 \mathrm{y}$, and menarche occurred at $12.3 \pm 1.2$ y (Table 1 ). In boys, gonadarche occurred at $10.3 \pm 0.5 \mathrm{y}$ and pubarche occurred at $11.4 \pm 0.7 \mathrm{y}$.

\section{Girls}

Figure 1 displays the relationships between thelarche, menarche, and pubarche age, and the length/height standard deviation scores (SDS) in the girls also shows the strengths of these correlations as a function of age to pubertal onset. The length/ height SDS correlated negatively and significantly with thelarche age from 15 mo of age $(P<0.0001$; Figure 1a), menarche

'Pediatric Department, Bnai-Zion Medical Center and Clalit HMO, Haifa, Israel; ${ }^{2 B i o i n f o r m a t i c s ~ K n o w l e d g e ~ U n i t, ~ T h e ~ L o k e y ~ C e n t e r, ~ T e c h n i o n ~-~ I s r a e l ~ I n s t i t u t e ~ o f ~ T e c h n o l o g y, ~ H a i f a, ~}$ Israel; ${ }^{3}$ The Ruth and Bruce Rappaport Faculty of Medicine, Technion - Israel Institute of Technology, Haifa, Israel. Correspondence: Alina German (alinagerman@gmail.com) 


\section{Articles $\mid$ German et al.}

age from 54 mo of age $(P=0.014$; Figure 1c), and pubarche age from 15 mo of age $(P=0.004$; Figure 1e). In all instances, the correlation strength increased with age.

Figure 2 displays the relationships between thelarche, menarche, and pubarche age and BMI in the girls. BMI correlated negatively and significantly with thelarche from 36 mo of age $(P<0.0001$; Figure 2a), menarche from $54 \mathrm{mo}$ of age $(P=$

Table 1. Tanner stages of pubertal development in 659 girls and 706 boys for whom a full set of data was available for analysis

\begin{tabular}{lc}
\hline Girls & Mean \pm SD \\
\hline Thelarche age (years) & $9.8 \pm 0.7$ \\
Pubarche age (years) & $10.3 \pm 0.7$ \\
Menarche age (years) & $12.3 \pm 1.2$ \\
Breast full maturity age (years) & $14.1 \pm 0.8$ \\
Pubic hair full maturity age (years) & $14.1 \pm 0.8$ \\
Puberty progression (years) & $2.5 \pm 1.0$ \\
\hline Boys ( $\boldsymbol{n}=\mathbf{7 0 6}$ ) & Mean \pm SD \\
\hline Gonadarche age (years) & $10.3 \pm 0.6$ \\
Pubarche age (years) & $11.4 \pm 0.7$ \\
Genital full maturity age (years) & $14.6 \pm 0.6$ \\
Pubic hair full maturity age (years) & $14.8 \pm 0.6$ \\
\hline
\end{tabular}

0.016; Figure 2c), and pubarche from age $84 \mathrm{mo}(P=0.002$; Figure 2e). In all instances, the correlation strength increased with age. Pubertal progression or duration did not correlate with length/height or BMI at any age.

An AR (Figure 3) was detected in $47 \%$ of girls (group 2; BMI SDS: $0.9 \pm 0.9$ at $7 \mathrm{y}$ of age), and no AR was detected in the remaining $53 \%$ (group 1); their $7 \mathrm{y}$ of age BMI SDS was $0.0 \pm 0.8$, which is smaller than that of group $2(P<0.001)$. In group 2 girls, thelarche and menarche occurred significantly earlier than its occurrence in group 1 girls $(P=0.030$ and $P=0.017$, respectively; Figure 4$)$. No significant difference was demonstrated between the groups in pubertal progression (from B2 to menarche) $2.6 \pm 0.1$ vs. $2.5 \pm 0.1 \mathrm{y}$ and in the height at $15 \mathrm{y}$ of age $(164.3 \pm 5.5 \mathrm{vs} .164 .1 \pm 6.5 \mathrm{~cm})$.

\section{Boys}

In boys, the age at gonadarche correlated negatively and significantly with height from 36 mo of age $(P<0.001$; Figure 5). The correlation strength did not changed with age and was smaller than that of the equivalent correlation strength in the girls. The age at pubarche correlated negatively and significantly with height from 24 mo of age $(P=0.007)$. The correlation strength did not change with age. The age at gonadarche and pubarche was not correlated with the BMI at any age. a

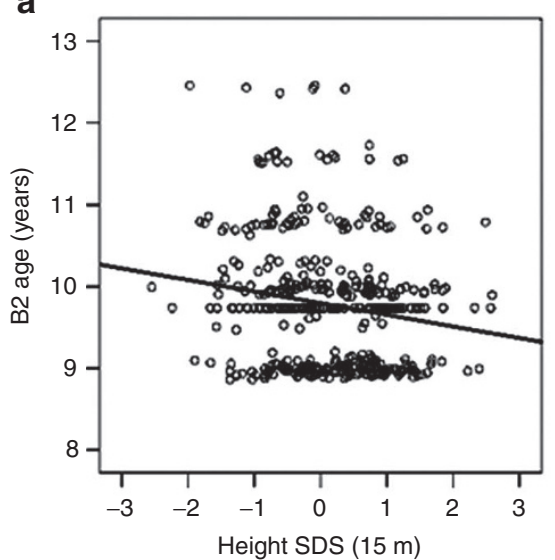

b

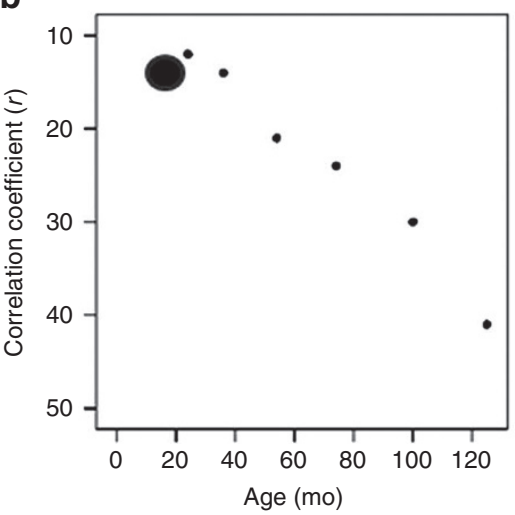

C

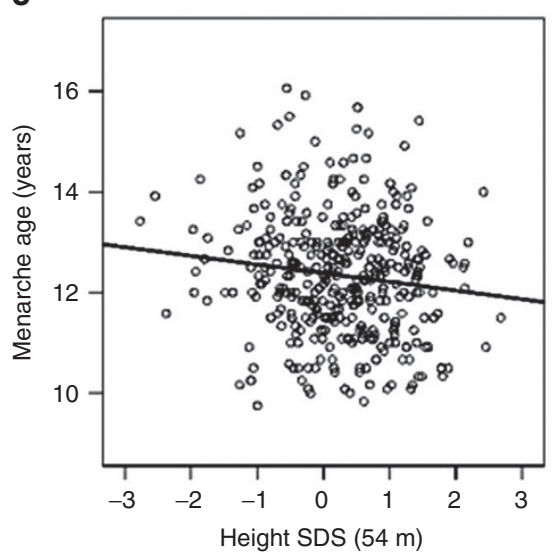

d

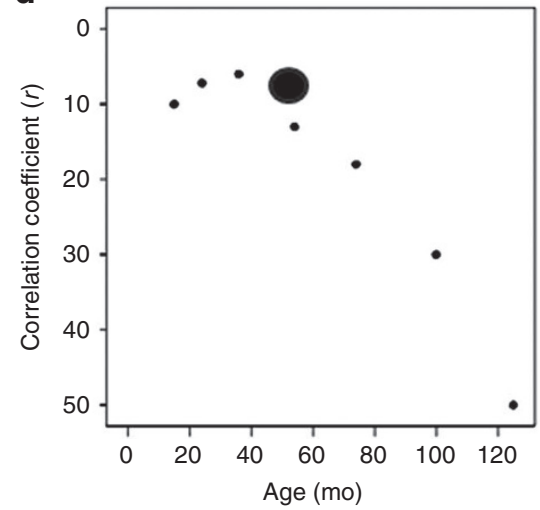

e

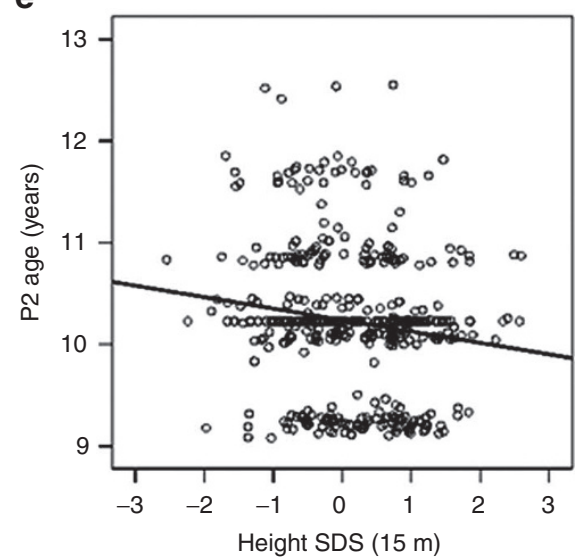

f

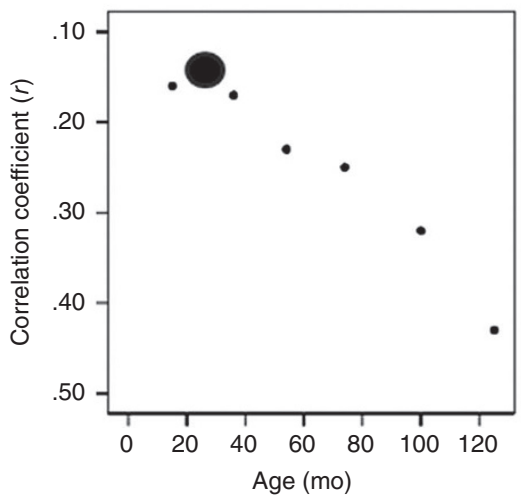

Figure 1. The relationships between thelarche, menarche, and pubarche age and the length/height standard deviation scores (SDS) in girls. (a) Thelarche age as a function of girls' length at the age of $15 \mathrm{mo}(r=-0.2 ; P=0.0001),(\mathbf{c})$ menarche age as a function of girls' height at the age of 54 mo $(r=-0.16 ; P=0.014)$, (e) pubarche age as a function of girls' length at the age of $15 \mathrm{mo}(r=-0.14 ; P=0.004)$. (b, $\mathbf{d}$, $\mathbf{f})$ Correlation coefficients as a function of age for thelarche, menarche, and pubarche. The bold dots indicate the age at which the correlations became significant $(P<0.05)$. 


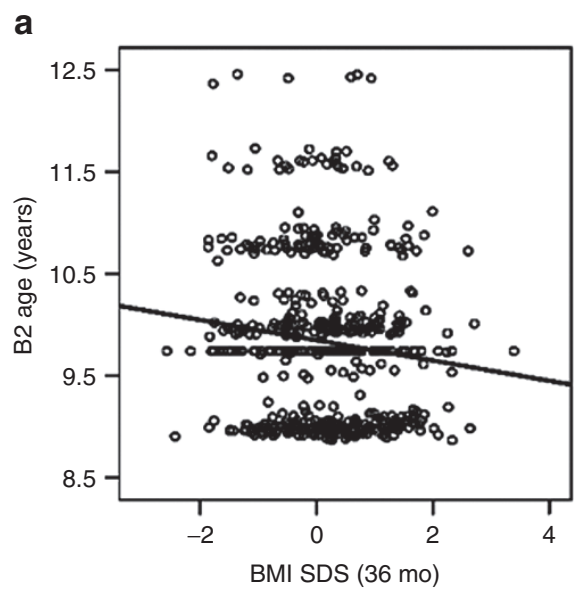

b

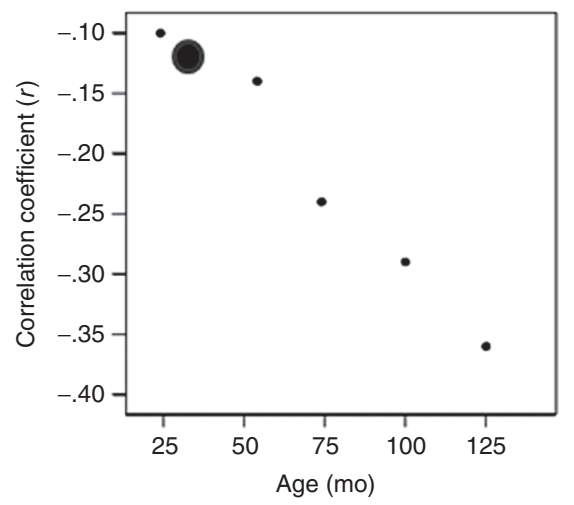

C

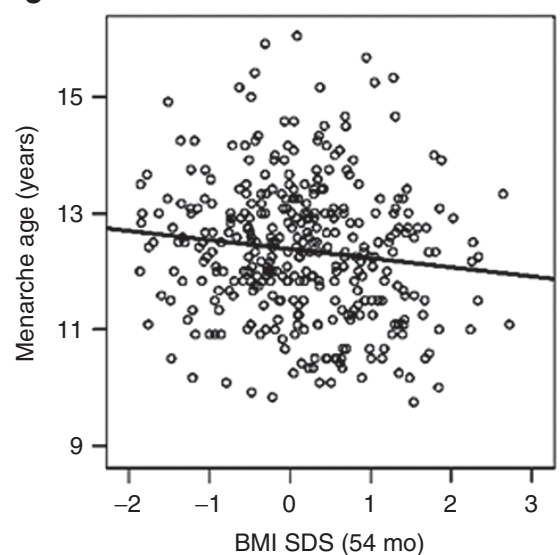

d

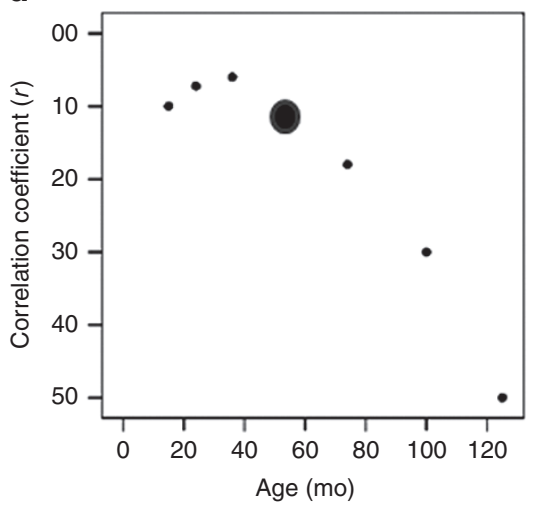

e

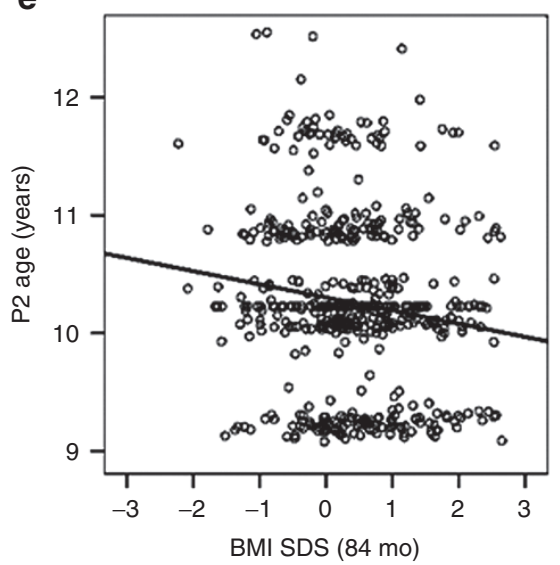

f

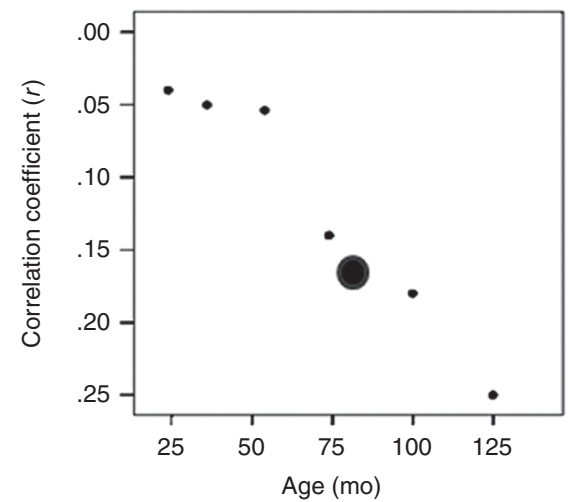

Figure 2. The relationships between thelarche, menarche, and pubarche age and BMI SDS in girls. (a) Thelarche age as a function of girls' BMI at the age of $36 \mathrm{mo}(r=-0.27 ; P=0.0001)$. (c) Menarche age as a function of girls' BMl at the age of $54 \mathrm{mo}(r=-0.16 ; P=0.016)$, (e) pubarche age as a function of girls' BMl at the age of $84 \mathrm{mo}(r=-0.14 ; P=0.002)$. $(\mathbf{b}, \mathbf{d}, \mathbf{f})$ The correlation coefficients as a function of age. The bold dots indicate the age at which the correlations became significant $(P<0.05)$.

An AR was found in $55 \%$ of the group 2 boys. These boys were heavier (BMI SDS: $1.1 \pm 0.9$ ) at $7 \mathrm{y}$ of age than the remaining $45 \%$ who had no AR (group 1; BMI SDS: $0.1 \pm 0.7$; $P<0.001)$. Pubarche $(P=0.020)$, but not gonadarche, occurred significantly earlier in the group 2 boys than its occurrence in group 1 boys, and puberty progression was faster $(P<0.001)$.

\section{DISCUSSION}

Children differ in the tempo at which they develop and mature to final height, body composition, and adult sexual and emotional maturity (3). Whereas height, BMI, and body composition are readily measureable, maturational tempo is mostly comprehended by assessing skeletal maturity, recording the age of occurrence of the pubertal stages, and a complex analysis of height SDS records $(3,12)$.

The role of adiposity in progression of the pubertal process has been previously reported as reviewed (1). Biro et al. (13) reported the onset of thelarche to be associated with race/ethnicity and BMI. In their study, girls with greater BMI reached breast stage 2 at younger ages. They also reported that girls who entered puberty through the thelarche pathway, as compared with the adrenarche pathway, had greater sum of skin fold thicknesses, BMI, and percent body fat $1 \mathrm{y}$ before the onset, as well as throughout, puberty (14). No associations between age at pubertal onset and simultaneous body composition were found (15). However, and from the same source, the heavier both boys and girls were at $7 \mathrm{y}$ of age, the earlier they entered puberty (16). Here, we present even earlier and sexually dimorphic predictive values for puberty age of height, $\mathrm{BMI}$, and the AR.

Our results indicate that length is the first predictor of pace pubertal process, the onset and duration of puberty (both thelarche and pubarche). The length becomes predictive as early as of 15 mo of age in girls and 36 mo of age in boys and the correlation between length/height and progression of puberty in girls is stronger than that in boys. In contrast, in girls the BMI becomes predictive of pubertal onset almost $2 \mathrm{y}$ later, at 36 mo of age, whereas the BMI shows no correlation with boys' onset of puberty.

Why do boys differ from girls in the control of their pace of the pubertal process? Whereas reproductive fitness applies mostly to females, sexual selection is challenging for most males. It is the female who needs to exploit any selection advantage in order to extend her fecund period through early maturation, which requires a secure energy supply and has currently reached historically unrecorded levels in industrial societies (4). She therefore programs for puberty by both length and BMI as early as 15 mo of age, while he will start program by 
a

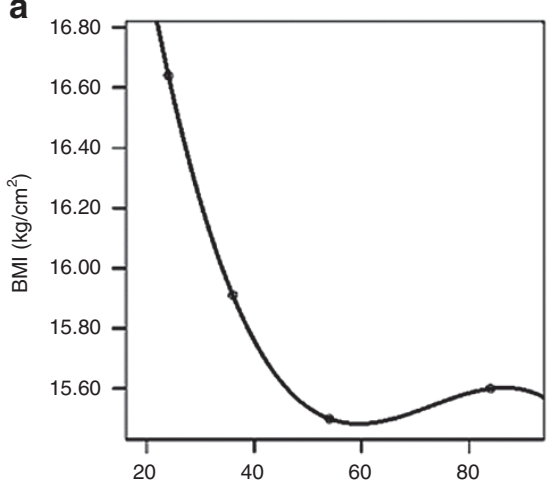

b

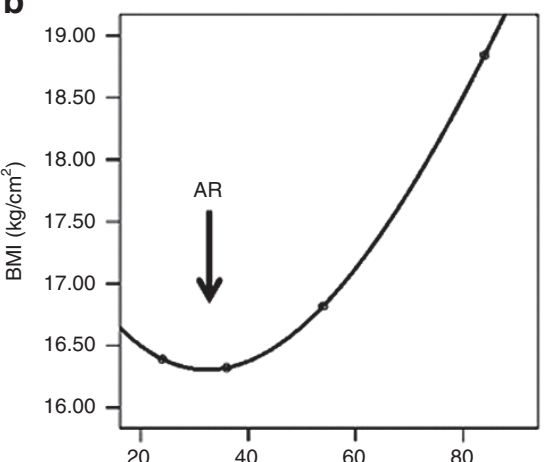

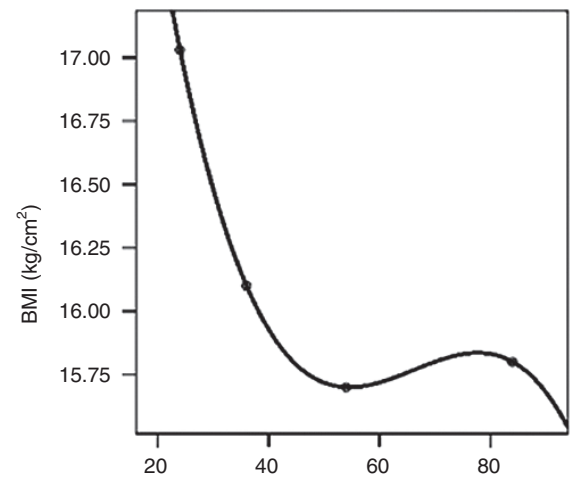

Age (mo)

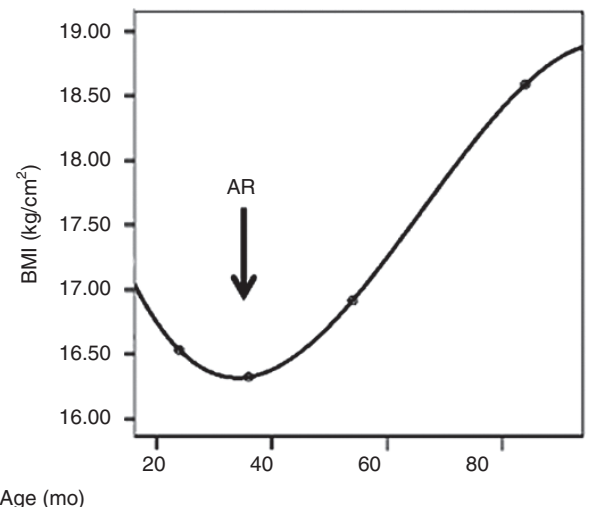

Figure 3. Average adiposity rebound (AR) patterns in boys (left) and girls (right). (a) Group 1 children show a decreasing BMI $\left(\triangle B M I 2-8=<0 \mathrm{~kg} / \mathrm{m}^{2}\right)$ and no adiposity rebound, and (b) group 2 children show an increasing BMI $\left(\triangle B M I 2-8=>0 \mathrm{~kg} / \mathrm{m}^{2}\right)$ and AR. AR was defined as nadirs of a second-degree polynomial regression of BMI between ages 2 and 10.

a

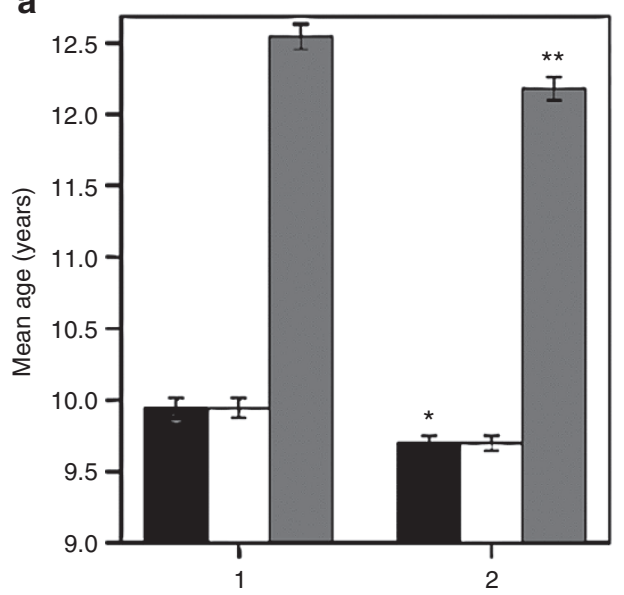

b

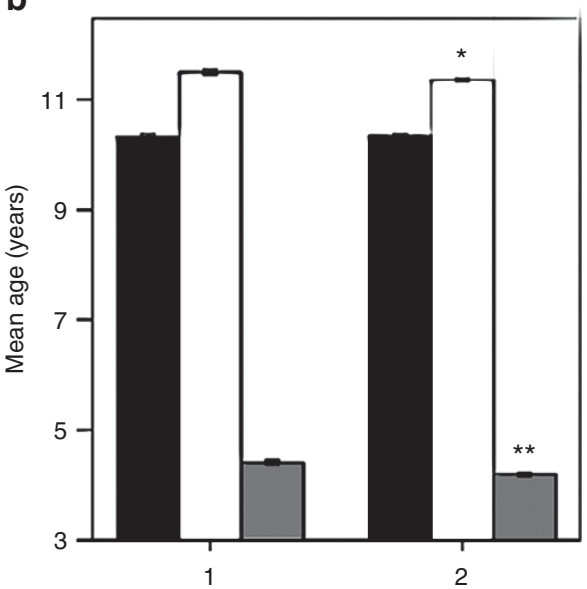

Figure 4. Comparison between the groups with adiposity rebound (AR) and no AR in the age at thelarche, pubarche, menarche (in girls) and gonadarche, pubarche, and puberty progression (in boys). (a) Age at thelarche (white), pubarche (black), and menarche (gray) for girls (left) divided into group 1 without adiposity rebound and group 2 with adiposity rebound. (b) Age at gonadarche (white), pubarche (black), and puberty progression (gray) in boys (right) without AR (group 1) or with AR (group 2). Mean \pm SD. Girls: ${ }^{*} P=0.030,{ }^{* *} P=0.017$. Boys: ${ }^{*} P=0.019$, ${ }^{* *} P<0.001$. AR, adiposity rebound.

36 mo of age and respond to height only-not to BMI. A late puberty, which would indicate later reproductive life (17), allows for a longer period of adolescent weight gain, as evident in underprivileged girls in developing countries (1). As much as the secular trend in human size is an adaptive response to a nutritionally rich environment, the receding age of pubertal development is an adaptive response to a positive energy balance. The current findings suggest that an individual's reproductive strategy is programmed during the ICT, which occurs around $1 \mathrm{y}$ of age. This finding is consistent with the life-history transitions theory (18), the ICT programming for adult height (19), and the theories of reproductive strategy (20). 
a

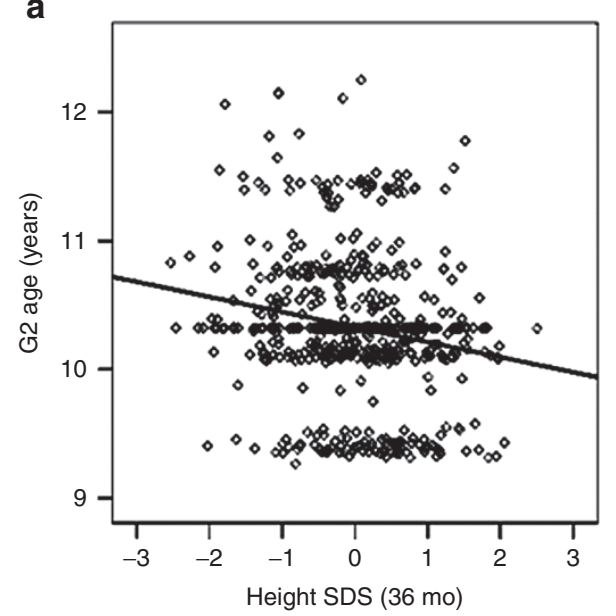

b

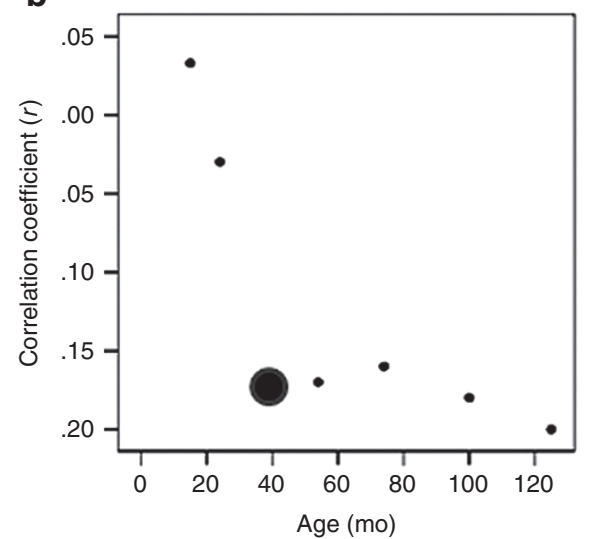

c

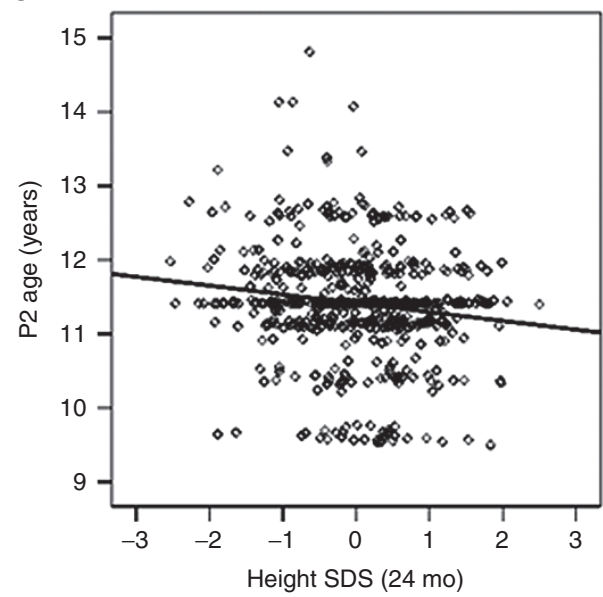

d

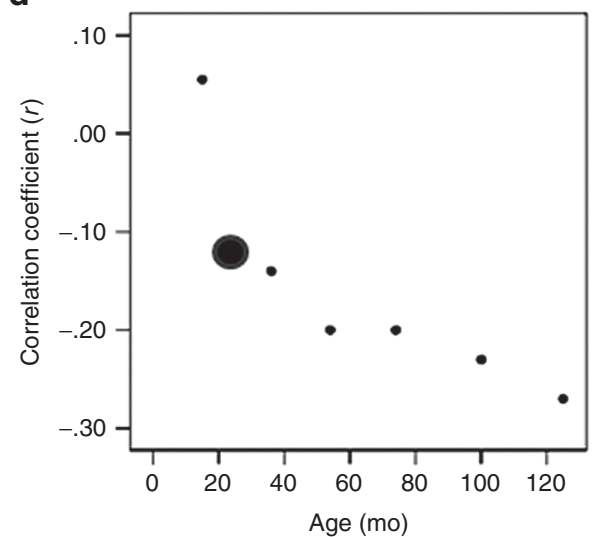

Figure 5. The relationships between genital development and pubarche age and the length/height standard deviation scores (SDS) in boys. (a) Gonadarche age as a function of boys' height SDS at the age of $36 \mathrm{mo}(r=-0.2 ; P=0.001)$, (c) pubarche age as a function of boys' height SDS at the age of $24 \mathrm{mo}(r=-0.12 ; P=0.007),(\mathbf{b}, \mathbf{d})$ the correlation strength as a function of age. The age that height and gonadarche age correlates stronger is $36 \mathrm{mo}$. The taller a boy is at the age of 36 mo the earlier he will enter puberty. The bold dots indicate the age at which the correlations became significant $(P<0.05)$. SDS, standard deviation scores.

Around $6 y$ of age, the BMI rebounds from a nadir $(8,9)$, and this rebound has been widely used as an index of childhood obesity and to predict adult obesity (10). Little is known about the provokers of the AR. In this investigation, we show for the first time that an AR only occurs in $47 \%$ of girls and $55 \%$ of boys in this American cohort and that these children become heavier at adolescence (9). The deflection from a decreasing to an increasing BMI parallels adrenarche and the decelerating growth during the transition from childhood to juvenility (21). We also found that early thelarche and menarche in children with an adipose rebound and the ages at which thelarche and menarche occurred correlated positively with the age of occurrence of the rebound. These findings are in agreement with the concepts of early growth, menarche, and AR that were proposed by Williams and Dickson in 2002: the timing of rebound is an indicator of physical maturity rather than obesity (22). Our finding of the existence of a temporal relationship between height at the ICT and the AR suggests that rebound might be programmed, at least in part, during ICT, in agreement with the ICT theory $(5,18,19)$.

The predictive value of the BMI rebound for maturational tempo differs in boys and girls. In boys, it predicts pubarche only, with intriguing implications for understanding those processes which stimulate adrenarche (23). In girls, it predicts the onset and duration of puberty. Its correlation with age at the onset of puberty and menarche places the AR as a marker, or even a mechanistic factor, which controls the maturational tempo. Interestingly, parental BMI was shown to be inversely correlated with the AR in offspring (22), a finding which suggests transgenerational imprinting of reproductive strategy by environmental or nutritional cues.

We have previously suggested that the AR and adrenarche are some of the manifestations of the childhood-juvenility transition (21). The AR becomes a measure of the amount of stored energy, and dihydroepiandrosterone is used a signal to prepare the brain for puberty and the ensuing fecundity (24).

In conclusion, an individual's maturational tempo is a twohit program. The first hit occurs at the ICT, which programs for height (19) and becomes a determinant of maturational tempo, as evidenced by the onset and duration of puberty. The second hit occurs at the childhood-juvenility transition, using adiposity and its rebound $(2,18,21)$ and is a second opportunity for an adaptive response to the environment. 


\section{METHODS \\ Subjects}

We analyzed longitudinal data of the NICHD SECCYD (11) whose participants were recruited from 24 hospitals in the United States and whose recruitment and selection are described in detail in previous publications $(11,25,26)$ and on the study's website http://secc.rti.org. Measurement and pubertal stage assessment were performed by the study network researchers. All study procedures were approved at the institutional reviews boards of each site, as previously reported (11), and parental informed consent was obtained for all participants.

The current analysis was made using data from 659 girls and 706 boys, who started the study in 1991. By the time they reached 9th grade, 469 girls and 540 boys were still followed. Of importance is the fact that when the analyses to be reported were run in comparison with complete data, results were not appreciably different (27).

The pubertal development of each child was determined annually by a physical examination which included Tanner staging, and the age of occurrence of each Tanner stage was recorded (28). In this analysis, we investigated the age at the onset of puberty (Tanner stages P2 (pubarche), B2 (thelarche), or G2 (male gonadarche)) and the age at menarche as a function of 15 and 24 mo length or childhood height and the BMI SDS from 15 mo of age. We defined "pubertal duration" as the time elapsed from thelarche, pubarche, or male gonadarche to adult features, as defined by Tanner stages B5, P5, or G5, and "pubertal progression" for girls as the time elapsed from $\mathrm{B} 2$ to menarche.

\section{The Adiposity Rebound}

The children were divided into two groups according to the direction of the BMI change between 2 and 8 y of age $(\triangle B M I 2-8)$. Group 1 comprised children with a decreasing BMI $\left(\Delta \mathrm{BMI} 2-8:<0 \mathrm{~kg} / \mathrm{m}^{2}\right)$ and group 2 comprised children with an increasing BMI ( $\triangle \mathrm{BMI} 2-8$ : $>0 \mathrm{~kg} / \mathrm{m}^{2}$ ) (Figure 1). In group 2, the age of occurrence of the AR was determined by calculating the nadir of a second-degree polynomial regression of BMI between 2 and $10 \mathrm{y}$ of age.

\section{Statistical Analyses}

Data were statistically analyzed using a computerized statistical software program (SPSS Statistics for Windows, Version 20.0; SPSS, Chicago, IL). An independent-samples $t$-test was used to compare the continuous variables of the two $\triangle \mathrm{BMI}$ groups. Pearson's productmoment correlation coefficients were used to determine the linear association between auxological parameters and the age at stages of pubertal development. Data are displayed as mean \pm SD, and statistical significance was set at $5 \%$.

\section{STATEMENT OF FINANCIAL SUPPORT}

No financial assistance was received in support of the study.

Disclosure: There is no conflict of interest to disclose.

\section{REFERENCES}

1. Parent AS, Teilmann G, Juul A, Skakkebaek NE, Toppari J, Bourguignon JP. The timing of normal puberty and the age limits of sexual precocity: variations around the world, secular trends, and changes after migration. Endocr Rev 2003;24:668-93.

2. Ellis BJ. Timing of pubertal maturation in girls: an integrated life history approach. Psychol Bull 2004;130:920-58.

3. Molinari L, Hermanussen M. The effect of variability in maturational tempo and midparent height on variability in linear body measurements. Ann Hum Biol 2005;32:679-82.

4. Hochberg Z, Belsky J. Evo-devo of human adolescence: beyond disease models of early puberty. BMC Med 2013;11:113.
5. Hochberg Z, Feil R, Constancia M, et al. Child health, developmental plasticity, and epigenetic programming. Endocr Rev 2011;32:159-224.

6. Cooper C, Kuh D, Egger P, Wadsworth M, Barker D. Childhood growth and age at menarche. Br J Obstet Gynaecol 1996;103:814-7.

7. Ong KK, Potau N, Petry CJ, et al.; Avon Longitudinal Study of Parents and Children Study Team. Opposing influences of prenatal and postnatal weight gain on adrenarche in normal boys and girls. J Clin Endocrinol Metab 2004;89:2647-51.

8. Eriksson JG, Forsén T, Tuomilehto J, Osmond C, Barker DJ. Early adiposity rebound in childhood and risk of type 2 diabetes in adult life. Diabetologia 2003;46:190-4.

9. Williams SM, Goulding A. Early adiposity rebound is an important predictor of later obesity. Obesity (Silver Spring) 2009;17:1310.

10. Dietz WH. "Adiposity rebound": reality or epiphenomenon? Lancet 2000;356:2027-8.

11. Network NECCR. The effects of infant child care on infant-mother attachment security: results of the NICHD Study of Early Child Care. Child Dev 1997;68:860-79.

12. Wolanski N. A new graphic method for the evaluation of the tempo and harmony of physical growth of children: the method of developmental channels and steps. Hum Biol 1961;33:283-92.

13. Biro FM, Greenspan LC, Galvez MP, et al. Onset of breast development in a longitudinal cohort. Pediatrics 2013;132:1019-27.

14. Biro FM, Lucky AW, Simbartl LA, et al. Pubertal maturation in girls and the relationship to anthropometric changes: pathways through puberty. J Pediatr 2003;142:643-6.

15. Mouritsen A, Aksglaede L, Soerensen K, et al. The pubertal transition in 179 healthy Danish children: associations between pubarche, adrenarche, gonadarche, and body composition. Eur J Endocrinol 2013;168:129-36.

16. Aksglaede L, Juul A, Olsen LW, Sørensen TI. Age at puberty and the emerging obesity epidemic. PLoS One 2009;4:e8450.

17. Hochberg Z, Gawlik A, Walker RS. Evolutionary fitness as a function of pubertal age in 22 subsistence-based traditional societies. Int J Pediatr Endocrinol 2011;2011:2.

18. Hochberg Z. Evo-devo of child growth II: human life history and transition between its phases. Eur J Endocrinol 2009;160:135-41.

19. Hochberg Z, Albertsson-Wikland K. Evo-devo of infantile and childhood growth. Pediatr Res 2008;64:2-7.

20. Belsky J, Steinberg L, Draper P. Childhood experience, interpersonal development, and reproductive strategy: and evolutionary theory of socialization. Child Dev 1991;62:647-70.

21. Hochberg Z. Juvenility in the context of life history theory. Arch Dis Child 2008;93:534-9.

22. Williams S, Dickson N. Early growth, menarche, and adiposity rebound. Lancet 2002;359:580-1.

23. Auchus RJ. The physiology and biochemistry of adrenarche. Endocr Dev 2011;20:20-7.

24. Campbell B. Adrenarche and the evolution of human life history. Am J Hum Biol 2006;18:569-89.

25. Belsky J, Steinberg L, Houts RM, Halpern-Felsher BL; NICHD Early Child Care Research Network. The development of reproductive strategy in females: early maternal harshness -> earlier menarche -> increased sexual risk taking. Dev Psychol 2010;46:120-8.

26. Belsky J, Houts RM, Fearon RM. Infant attachment security and the timing of puberty: testing an evolutionary hypothesis. Psychol Sci 2010;21:1195-201.

27. Pluess M, Belsky J. Differential susceptibility to parenting and quality child care. Dev Psychol 2010;46:379-90.

28. Belsky J, Steinberg LD, Houts RM, et al.; NICHD Early Child Care Research Network. Family rearing antecedents of pubertal timing. Child Dev 2007;78:1302-21. 